\title{
Los sistemas de interpretación
}

\author{
Rolando Tamayo y Salmorán
}

El pardelismo que hoy existe entre la cicn. cia juridica dogmática y la teología ortodoxa salta a la vista. Por un lado, se habla de Dios, por el otro, del legislador; ambos seres inaseguibles a la experiencio, La masa profana desconoce sus intenciones o las conoce sólo de modo confuso. Una casta pri. cilegiada de teólogos o de juristas es media. dom de las retulaciones.

Hermann Kantorowicz.

\section{Introducción}

1. La interpretación. Interpretar consiste en dotar de significado, mediante un lenguaje, ciertas cosas, signos, fómulas o acontecimientos (objeto significado). Cabe afirmar, pues, que de manera general, interpretar es determinar o asignar el sentido a ciertos hechos, signos formulas 0 palabras.

El intérprete es una especie de mediador que comunica a los demás (generalmente en lenguaje común) el significado que él atribuye a ciertas cosas, signos o acontecimientos.

Los romanos llamaban interpres -intérprete, adivino- al que juzgaba de lo venidero por las entrañas de sus víctimas.

Fsto es, el intérprete pone en conocimiento de los demás el sentido que (según el, o de acuerdo con cierto método) corresponde a determinados objetos. Así, por ejemplo, los brujos, augures o sacerdotes no hacian 
sino dotar de sentido ciertos hechos, formulas o signos misteriosos que. en razón de su posición o poder, sólo ellos manejaban y entendían (o hacfan creer que entendian). En esta situación se encontraban, v.gr., los pontífices (antes de la indiscreción de Cneo Flavio) en relación con las fórmulas del derecho, formulas que solo ellos conocían y que interpretaban a petición de los legos. Los primeros jurisconsultos eran sacerdotes $y$ esto no puede sorprender. El derecho primitivo nace siempre en íntima relación con la religión y la magia; $y$, aún en épocas posteriores, conserva algo de ambas cosas. Inclusive, cuando la cultura comienza a decaer y el derecho a degenerar, renace a menudo esta conexión entre derecho y religión, como lo demuestra la Edad Media con sus "juicios de Dios: Asf, vemos en la Roma Arcaica que eran los sacerdotes quienes disponian de formulas rígidas para la celebración de contratos y los ritos procesales. El colegio sacerdotal designaba cada año a uno de sus miembros para que diera consultas juridicas al público, basándose en estas fórmulas monopolizadas por el sacerdocio y registradas en los libri pontificiales.

En ocasiones, la investidura mística del intérprete (magos, oráculos o sacerdotes no en el sentido romano) y del desconocimiento de sus métodos o procedimientos de significación, o mejor de interpretación, originó en gran medida la creencia de que estas personas posefan (en virtud de su situación o, incluso de una misteriosa razón) la aptitud, a veces extraña y sorprendente, de poder encontrar o desentrañar el sentido de las cosas.

Sin embargo, cualquiera que inquiera por el sentido que guardan ciertos objetos o signos y dé unia "respuesta" se encuentra asignado un significado a dichos objetos o signos. Significado que podrá ser o no ser compartido, ser o no ser debido, etc., pero en todo caso, es un acto que otorga sentido a los objetos, sentido, del cual carecen de esta atribución de significado.

El sentido es siempre incorporado mediante la interpretación, pero ni se busca ni se desentraña. Dicen los académicos, al respecto, que 'interpretar' consiste en declarar el sentido de una cosa.

Las cosas, los signos, etcétera, no tienen, en consecuencia, un sentido en sí; las cosas o los signos adquieren cierta significación en virtud de un acto de establecimiento de sentido.

"Los elementos o componentes semánticos son Hamados interpretativos en la medida que ellos interpretan los signos o componentes sintácticos": 
2. Interpretación de un lenguaje. Ahora bien, el objeto por interpretar bien puede ser un lenguaje (o los términos de un lenguaje).

"En cualquicra investigación sobre el lenguaje existe un lenguaje objeto que constituye el objeto de la investigación y existe un metalenguaje usado por los investigadores para hablar del lenguaje objeto. Debe enfatizarse que el lenguaje objeto y el metalenguaje son términos relativos. Cualquier lenguaje, no importa lo simple o complejo que éste sea, es un lenguaje-objeto cuando se habla de él. $\mathrm{Y}$ cualquier lenguaje es un metalenguaje cuando es usado para hablar (to discuss) de un lenguaje objeto":

En este caso, la función significativa de la interpretación consiste en la incorporación o asignación de un sentido a ciertos signos, expresiones o palabras a fin de hacerlos corresponder con determinados objetos. "En términos generales, una interpretación consiste en asignar sistemáticamente unos objetos denotados a parte de vocabulario primitivo".

Que un lenguaje (o los térninos de un lenguaje) sea el objeto de una interpretación no representa ningùn problema particular. ¿Acaso no vivimos cómo el diccionario interpreta o significa el término "interpretar" para hacerlo corresponder a cicrto objeto, en el caso: "el acto de declarar el sentido de una cosa"'?

La interpretación de un lenguaje es la significación que se incorpora a un lenguaje (o a los términos de un lenguaje) -el lenguaje intepretadomediante otro lenguaje -el lenguaje significativo.

"Al establecer una interpretación para un sistema formalizado enunciando explicitamente las reglas semánticas, empleamos otro lenguaje, el llamado metalenguaje. (Se supone que entendemos el metalenguaje). Las reglas semánticas están encuadradas en el metalenguaje y enuncian específicamente que las expresiones apropiadas del sistema lingüístico dado denotan tales y cuales objetos; dando por supuesto que entendernos el metalenguaje, llegamos también a entender el lenguaje-objeto, y el procedimiento de interpretación se hace explicito de este modo".

El lenguaje interpretado o lenguaje objeto puede ser simbólico, ideográfico, algoritmico o ideomático; asi como verbal o escrito.

Es bastante habitual considerar que 'interpretar' se refiere normalmente a establecer o declarar el sentido de un texto. 
3. El Lenguaje Juridico y st Interpretación. Una de las particularidades que ofrecen los objetos conocidos como formando la experiencia juridica es que constituyen un lenguaje o se presentan como lenguaje. A este lenguaje bien podemos denominarlo lenguaje jurídico.

Desde la invención de la escritura existió la posibilidad de formular el derecho (o gran parte del derecho) por escrito. Célebres son los momentos en la historia institucional en que se ordenó o sistematizó el derecho mediante grandes compilaciones o codificaciones, buscando la fijación del derecho. De entre las grandes codificaciones, una, sin embargo, es de particular interés para la interpretación jurídica: el Código Civil francés de 1804.

Si ciertamente el código civil francés cambió el planteamiento de la interpretación del derecho - particularmente de la ley-el problema de la interpretación surgió como corolario del advenimiento del ius scriptum. Antes de abordar el tema de la interpretación de la ley, es necesario exponer algunos antecedentes, en materia de interpretación del derecho escrito, así como señalar las características que corresponden a la ley (en sentido moderno).

\section{Antecedentes (Sobre la interpretación del derecho escrito).}

Dos momentos han sido de enorme importancia para la interpretación jurídica: la interpretatio y los glosadores. Son en ellos donde se encuentran prácticamente todos los antecedentes de las reglas de la hermenéutica.

1. Interpretatio, En un principio, en Roma, los pontifices, de ma. nera exclusiva realizaron la tarea de interpretar el derecho. Tarea que después fue asumida por los jurisconsultos: hombres entendidos en derecho. El hecho de que los pontífices hayan sido los primeros jurisconsultos es un dato que no puede sorprender.

En efecto, el derecho primitivo nace siempre en intima relación con la religión y la magia, $y$, aún en épocas posteriores, conserva algo de am. bas cosas. Inclusive, cuando la cultura comienza a decaer y el lerecho a degenerar, renace a menudo esta conexión entre derecho y religión, como lo demuestra la Edad Media con sus 'juicios de Dios'. Así, vemos en la Roma Arcaica que eran los sacerdotes quienes disponian de formulas rígidas pari la celebración de contratos y los ritos procesales. W, read that 
pontifical college delegated This Junetion anually (Shultz, p. 20). El colegio sacerdotal designaba cada año a uno de sus miembros para que diera consultas jur fdicas al público. basándose en estas fórmulas monopolizadas por el sacerdocio y registradas en los libri pontificiales.

Como las Doce Tablas no podrán satisfacer el incremento de las necesidades jurídicas, se recurrió a la interpretatio.

"La interpretación de las XII Tablas y del rico repertorio de formularios procesales y negociables que se venían transmitiendo, siguió siendo hasta comienzos del siglo III un monopolio celosamente custodiado por el Colegio de pontifices ('ponteneros')":

"La historia de la jurisprudencia romana empieza con los pontifices. Conocedores de la magia y teniendo a su cargo la confección del calendario del Estado Romano, pues ésta fue seguramente su función primitiva, los pontífices dominaron, probablemente desde tiempo, no sólo las reglas para que se comunicara la ciudad con los dioses (el jus sacrum), sino también las fórmulas para litigar en el proceso romano arcaico y fórmulas para la conclusión de negocios juridicos. Porque los romanos de la época primitiva pensaban que en las relaciones juridicas entre los hombres, al igual que en la oración, todo dependia del empleo de las palabras adecuadas; sólo el que sabía la fórmula apropiada podía obligar a la divinidad y vincular o desvincular a los hombres. Como todos los actos mágicos, el saber de los pontífices era, de suyo, secreto: el tesoro de fórmulas que encerraban el archivo del colegio (los libri pontificales) durante mucho tiempo sólo fue accesible a sus miembros y únicamente a su seno se transmitieron de generación en generación los métodos de aplicación del derecho que ellos habian desarrollado y practicado".

Con el fin de satisfacer nuevas necesidades, los sacerdotes, mediante la interpretatio, cambiaron, por mucho, el sentido original de las XII Tablas.

Asi, la interpretatio prudentium se convirtió en una 'fuente del derecho' (en un procedỉiniento creador del derecho) puesto que extendió la legislación de los decemviri a nuevas situaciones juridicas.

La interpretatio prudentium fue el método que sirvió para convertir el derecho consuetudinario (sino scripto) en una de las formas del âs scriptum.

En efecto, la interpretatio prudentium fue considerado ius non 
scriptum, pero en las institutas de Justiniano (i.2.3.) los responsa de los juristas fueron enlistados entre las demás formas del ius scriptum.

La interpretatio no se concretó sólo a la aplicación de las XII Tablas. La actividad interpretativa de los jurisconsultos romanos se hizo patente también cuando aparecen los leges y los edictos pretorianos.

En un último momento, en el Imperio, la interpretación del derecho escrito (de las compilaciones) llegó a ser una facultad especial del emperador, $\mathrm{Y}$ asf Justiniano declaró enfáticamente que el Emperador, en tanto el legislador exclusivo, tiene el derecho exclusivo de interpretar el derecho (qui soli concensum est logos interpretari).

Los intérpretes iuris, en su tarea de extender el derecho, llegaron a establecer reglas y formular principios jurídicos. De ahí que el interpres fuera llamado 'aquel' que iura condidenunt' (aquel que establece el derecho). Los romanos no elaboraron una teoría de la interpretación; empero en el Digesto nos legaron un conjunto de sus reglas.

2. Los Glosadores. Los glosadores se dedican al estudio del derecho justinianeo (aunque también, en alguna medida, al derecho canónico y germánico).

Su función se caracteriza (o en todo caso así lo conciben), en explicar el sentido del texto legal. Para ellos no hay más derecho que el corpus auris civilis.

Subyugados por el krado de perfección del derecho. y de la doctrina jurfidica ahí reunida, ven en el Corpus luris no un derecho sino el derecho. El derecho, según su concepción, se ha dictado de una vez y para siempre y se encuentra, justamente, en las sentencias del Corpus luris Civilis.

Su método se caracteriza por realizar anotaciones de carácter aclaratorio (entre las lineas o al margen) para explicar el sentido del texto -glosae.

Aunque los glosadores conciben la idea de que solamente explican el sentido del texto, las glosas les permiten trazar antagonismos y paralelismos entre las diversas reglas, lo cual representa un grado de sistematización que se aleja de una mera interpretación literal

Las summae son glosas que resumen el contenido de un cuerpo o de 


\section{LOS SISTEMAS DE INTERPRETACION}

una sección del corpus turis. Glosas que demuestran un grado elevado de sintesis. Los brocarda por su parte son glosas que formulan reglas generales en donde los glosadores intentan hacer desaparecer las antinomias del texto. Esto último nos permite observar que, aunque los glosadores se limitan a explicar el sentido del texto justinianeo, en realidad su método alejándose de la interpretación literal y formulando sistematizaciones que les permiten producir, gran cantidad de doctrinas. En las questiones dispuntatae, p.e., los glosadores se alejan completamente del texto de la ley discutiendo en un terreno doctrinal establecido argumentos pro et contra.

Un ejemplo nos servirá para constatar lo dicho: Modestino define el matrimonio como dividum acue humane iuris comunication. Sentencia que los glosadores interpretaron en el sentido de que profesar distinta religión es impedimento para celebrar matrimonio.

Se suele seffalar a la escuela de los comentaristas como otro antecedente de la interpretación legal.

Los comentaristas, en mayor grado que los glosadores, tienden a separarse del análisis literal. En efecto, los comentaristas aspiran a la construcción de una teoría general.

Es característica de la escuela de los comentaristas, el uso del método escolástico para comentar el derecho romano, $o$, las más de las veces, la interpretación que hicieron de él los glosadores.

Existe una decidida diferencia entre los primeros glosadores y los comentaristas, "los primeros glosadores tenfan la ventaja de encontrarse constrefiidos a considerar directamente las fuentes mismas; $y$ tales constituían su objeto. Bartolo, por el contrario, tenian por objeto los escritos de los glosadores que habian vivido entre él y las fuentes... ésta es una de las razones por las que la escuela de Bartolo es $\tan$ inferior a la de los glosadores":

Esta escuela, sin embargo, no fue muy trascendental para la evolución del derecho. Se limitó a estudiar cuestiones secundarias, llevando a cabo divisiones y subdivisiones; sometiéndose a argumentos de autoridad sin un espiritu critico.

3. La legislación en los tiempos modernos. a) El mito de la ley. Antes de explicar la exégesis francesa y su objeto primordial, la interpre- 
tación de la ley, es necesarió conocer lo que significó la legislación en el constitucionalismo y el liberalismo del siglo XVIII. En tal contexto. la ley es el conjunto de normas escritas, abstractas y generales, producidas por un cuerpo legislativo especial.

Una de las caracteristicas de la ley es su manifestación por escrito. 'Lex' proviene del verbo latino 'lego' 'legare' que significa leer. (Cfr. Aftalión). Sólo se puede leer las disposiciones escritas. La importancia de la ley escrita en el siglo XVIII es que, en combinación con su carácter imnersonal y abstracto, satisface el ideal de un 'Estado de derecho'. Efectivamente, sólo por la palabra escrita pueden garantizarse los derechos ciudadanos, estableciendo, así, un sistema de competencias para los gobernantes. Sólo constando por escrito, en un pacto solemne (como lo es la ley, por ej., la ley constitucional), se garantiza un 'Estado de derecho'. Un ejemplo de esta concepción es la constitución de Virginia de 1776. en la cual se garantizan, por escrito, los derechos de los ciudadanos.

El carácter impersonal y abstracto de la legislación satisface el ideal de la teoria liberal de la igualdad ante la ley. De esta manera se garantiza un 'Estado de derecho' donde no existan situaciones jur idicas de excepción.

Si la legisłación se presenta como la 'fuente del derecho' más importante en Europa Continental; se debe, entre otras cosas, al hecho de que la legislación presenta una regla formulada, lista para su aplicación satisfac iendo certeza y economía procesal.

Pero, si los individuos se sienten obligados a aplicar la legislación es que ella es una manifestación (más o menos inmediata) de la soberanía; la cual se encuentra encarnada en los cuerpos legislativos.

De conformidad a la teorfa de la división de poderes, son los cuerpos legislativos los que transmiten la voluntad ciudadana en leyes; voluntad ciudadana que nunca se equivoca; es la volonté generale de J.J. Rousseau. Es pues, esta ideología normativa (Cfr. Ross), la que se encuentra atrás de la ley y la mistifica.

No hay que olvidar que el siglo XVIII fue la era del racinnalismo. Entonces se crefa posible determinar un cuerpo de normas unive salmente vátidas e inmodificables, aplicable a todos los países, a partir del conocimiento de la naturaleza del hombre. Un ejemplo típico de esta concepción es el Código Napoleón. 
Es necesario distinguir a la legislación de las compilaciones o recopilaciones (tales como el Digesto, las Constituciones, el Real Patrimonio o el Fuero Juzgo, que codificaban el derecho ya existente). Por legislación se entiende, en el siglo XVIII, un procedimiento que conscientemente crea o establece un derecho nuevo (producto racional de los cuerpos legislativos).

\section{La Escuela de la Exégesis}

1. Contexto e ideología normativa. En este contexto ('El Estado de Derecho'), racionalismo, liberalismo, constitucionalismo, etc.), se genera en Francia un culto al texto de la ley y una fe ciega en su virtud. Características inseparables de la escuela de la exégesis.

Habria que indicar que la escuela de la exégesis fue resultado necesario de la legislación (entendida como un producto racional y como manifestación -directa o indirecta-de la soberania nacional).

"Jamás escuela alguna hizo una profesión de fe más rígida, más completa, más dogmática, que la escuela de la exégesis"

La escuela de la exégesis francesa (cfr. Julián Bonnecase) tuvo tres fases: la fundación (1804-1825), el apogeo (1830 a 1880) -a este período pertenecen los grandes comentadores del Código Napoleón-y la decadencia $(1880-1900)$.

Durante la fundación de la escuela, sus miembros no son muy numerosos. En este período, no había influido sobre los espiritus la aparición del código civil, por lo menos no hasta el grado de hacer desaparecer de una manera inmediata la concepción del derecho que habia existido en siglos anteriores (V, nota $4, J$ Julián Bonnecase). De esta primera época el miembro mís sobresaliente, por su fidelidad exegética es A. Duranton (profesor en la Faculté du Droit de París cuyo curso de derecho francés de acuerdo al código civil comenzó a publicarse en 1825). Es de señalar que en esta primera etapa sus miembros fueron, en su mayoria, profesores universitarios.

La segunda fase estả compuesta de cantidad de autores y profesores. también de magistrados, litigantes y abogados. A este período corresponden las frases tristemente célcbres del profesor Bignet ("no conozco el derecho civil, enseño el Código Napoleón". Pertenecen a esta fase grandes profesores como: Aubry (Prof. de Estrasburgo), Rau (Prof. de Estrasbur- 
go) autores de la obra maestra de la exégesis; Denolombe (Prof, de Caen). Taullier, Demante y el primer presidente de la Corte de Casación: Tropolong, etc.

A la última fase de esta escuela pertenecen los últimos ortodoxos $y$ aparecen algunas tentativas renovadoras de los principios de esta escuela. Entre los más famosos miembros de esta época. se encuentran Baudry Lacantineric, Labbé, Bufnoir. Salelles y Beudant. Estos últimos representaron, de acuerdo con Bonnecase, una tentativa de renovación que aparentemente fue vana. Según Bonnecase, esta âltima etapa fue simplemente una transición entre la exégesis y la escuela científica francesa.

2. Las características de la escuela. Varios rasgos caracterizan a la escuela de la exégesis: a) El culto del texto de la ley. b) Considerar la 'voluntad del legislador' como pauta suprema de interpretación. c) Considerar al 'legislador' omnipresente y omnisapiente. El más característico es el primero. El derecho positivo se identifica por completo con la ley.

A este respecto, son célebres las palabras de Laurent: "Los códigos no dejan nada al arbitrio de un intérprete, éste no tiene ya por misión hacer el derecho: el derecho está hecho. No existe incertidumbre, pues el derecho está escrito en texto auténtico" (Cours Elémentaire du Droit Civil T. L. Prefacio p. 9). En el mismo lugar, Laurent dice: "haciendo el derecho, los tratadistas, los magistrados o jueces usurparian el poder que la ación soburana ha otorgado al cuerpo legislativo ( $\mathrm{ibidem}$ ).

Segunda 'característica', la ley es resultado de la 'voluntad' del legislador. Es el espiritu del legislador el guía seguro para comprender la 'ctra de la ley. La misión del jurisconsulto no es otra más que determinar ta "voluntad del legislador".

Para entender la segunda característica de la escuela de la exégesis, nada más claro que las palabras del profesor Aubry: "frecuentemente y, por interpretar la ley a su arbitrio que por buscar el verdadero sentido de ella, han sobrepasado los límites asignados a la interpretación. Los profesores, encargados de impartir, a nombre del Estado, la enseñanza jurídica, tienen por misión protestar, mesurada, pero firmemente, contra toda innovaciòn que tienda a substituir la voluntad del legislador por t ia extraกล"

El sentido del texto de la ley se encuentra - dice el profesor Taullier- by sando el fato que alumbró al mismo 'legislador'. En cuanto 
al procedimiento para encontrar la 'voluntad del legislador', la escuela no es constante; pero tampoco parece ser que ese tema les haya preocupado demasiado. Pareciera que todos conocian la 'voluntad del legislador' y que, en dado caso, sabían cómo encontrarla.

Sin embargo, algunos proponian ciertos métodos asi, por ejemplo, Demolombe sostiene que dicha intención puede encontrarse en una jurisprudencia definida (Cours du Code Napoleon T. I. p. 135 cit. por J. Bonnecase $o p$. cit., p. 151). Los profesores Aubry y Rau seflalan que para encontrar la 'voluntad del legislador' es necesario proceder a 1) la comparación del texto que se va a interpretar, con las demás disposiciones legales relativas a la misma materia o materias análogas; 2) la investigación de los motivos o del objeto de la ley en los trabajos preparatorios a su redacción o en el derecho anterior; y 3 ) la apreciación de las consecuencias a que conduciría una aplicación extensiva o restrictiva del alcance de la ley, todo esto para verificar si el legislador hubiera querido los efectos de estas interpretaciones":

La idea de la 'voluntad del legislador' revela -dice Bonnecase- el carácter ficticio de la doctrina.

Otro rasgo de la escuela de la exégesis es la idea de la omnisapiencia del legislador. El culto al texto de la ley y a la intención del legislador, coloca a la escuela de la exégesis ante un legislador omnipotente, omnisapiente, completamente racional. FI legislador, en este orden de ideas, es completamente racional $\mathrm{e}$ infalible. De ahí que Mourlon declare que "en jurisprudencia no hay ni puede haber mayor razón ni mejor equidad, que la razón o equidad de la ley."

3. La interpretación de la ley. Sobre interpretación de la ley se podrian señalar cuando menos, dos métodos: 1) el exegético puro, 2) el sistético. El primero reduce la exposición del derecho, no únicamente al código, sino, también, al orden de las disposiciones del código.

De esta manera, el poder judicial cuenta para sus decisiones con un plan y un orden ya preparado que son los libros, los títulos, los capítulos, las secciones del codigo civil y dentro de las secciones el orden mismo de los articulos.

En ambos casos, la obra del autor no sería más que un comentario del contenido de los artículos del código. Esta explicación no es más que una resena analítica del sistema del código. El segundo método supone 
que la observación de los datos sociales es un fait accompli realizado exclusivamente por los redactores del código.

Los redactores allanaron asi la investigación del jurisconsulto, obligándolo por tanto a situarse dentro del conjunto de las reglas dictadas. Puesto que los datos históricos fueron observados $-\mathrm{y}$ sistematizados - por el legislador, los jurisconsultos no se preocupan ya por las divisiones usadas por los redactores del código, sino que examinan los textos tomando divisiones propias, presentando en forma original el objeto de la reglamentación del código. En ambos casos, la obra del autor no sería más que un comentario del contenido de los artículos del código. Es por ello comprensible que Demolombe declara, en cuestiones de interpretación y comentario, "Los textos ante todo". Para interpretar la ley es necesario desprenderse de los prejuicios.

Tal como recurrir al derecho antiguo (coutumes), o al derecho romano para explicar el derecho civil; éste sólo dañaría la "ciencia' racional del derecho.

"Es en el Código Napoleón donde debe estudiarse el Código Napoleon". Todo se encuentra contenido en la ley, basta simplemente aplicarla. aplicarla.

Teniendo en cuenta las caracteristicas racionales en las que se basaba un código (en el caso la compilación prusiana), Federico II prohibió en absoluto toda interpretación; de modo que la decisión del juez consistiera en una mecánica aplicación del mismo y quiso que, en caso de silencio o de ambigùedad en la ley, se debia siempre consultar al poder legislativo. Es necesario recordar que, para ambos métodos, en caso de incertidumbre - laguna de la ley, sólo habría que buscar, como indicamos, la 'voluntad del legislador'.

4. Importancia. Es innegable la importancia de la escuela de la exégesis particularmente en el campo del derecho civil. Puede decirse, sin lugar a dudas, que la construcción doctrinal que produce es el punto de partida del moderno derecho privado del mundo occidental.

5. Critica. Muchos autores han atacado la superficial idolatria de la ley que caracteriza a la escuela de la exégesis francesa.

Savigny (Sistema del Derecho Romano Actual, De la Vocación de nuestro Siglo para la codificación y la Ciencia del derecho): Pushta (El De- 
recho Consuetudinario) y Allen (Law in the Making) señalan, como lo habian hecho algunos detractores de la exégesis, que existe derecho incluso donde la ley falta.

La crítica fundamental a esta escuela consiste en señalar la reducción del derecho a la simple manifestación escrita de la ley, así como su creencia en métodos idóneos que nos llevarian, a conocer, sin lugar a dudas, la 'voluntad del legislador'.

\section{La Escuela Histórica Alemana}

1. Contexto e ideologia nomativa. La escuela histórica floreció en Alemania.

De acuerdo con la escuela histórica, el derecho como el lenguaje -o el arte-se crea espontánea, constante e imperceptiblemente en un determinado pueblo. El derecho no es un producto de una razón humana abs. tracta sino es el resultado del Volkgeis (del espíritu del pueblo). Al carácter estático y exterior de la regla jurídica legislada, la escuela histórica opone la vida misma del derecho. Sostiene Von Savigny que el derecho se crea por las costumbres y las creencias populares, luego por la jurisprudencia, pero no por el arbitrio de ningún legislador.

Hay que desechar la legislación; la manera cómo deben tomarse las decisiones es más fácil introducirlas de las aplicaciones que lograron su fin (o de las que no lo consiguieron) que determinarlo, por medio de reglas generales.

2. Características de la escuela. La principal característica es la inclusión del espiritu histórico en el análisis de las instituciones: única garantia contra el racionalismo.

Ante el arbitrio del legislador y de la reducción del derecho a la ley es necesario recurrir al riguroso método histórico aplicado a la jurisprudencia. La caracteristica de este método es encontrar hasta en su raíz toda la doctrina del pasado y descubrir su principio orgánico.

Lo que se pide al estudio del derecho no puede ser depositado en un libro solemne ni puede ser confiado a la custodia de un limitado número de doctos, debe pertenecer a todos los juristas teóricos y prácticos porque, en jurisprudencia, es preciso que la teoria tenga mucho de práctica y que la práctica sea cientifica (tal es el modelo de la jurisprudencia romana clásica). 
3. Interprefación de la ley. Savigny estima que para interpretar y conocer el derecho es necesario poseer un conjunto de principios que se manifiestan en virtud de un hibito prolongado y fundado en solidas bases que permitan argumentar juridicamentc.

A este respecto, es significativo lo que Savigny señala sobre la jurisprudencia romana clásica (se refiere al siglo de Papiniano y de Ulpiano) "La idea y los teoremas del derecho no aparecen en los jurisconsultos romanos como creación arbitraria, antes bien, son verdaderos seres reales, cuya existencia y genealogía se les ha manifestado en virtud de un hábito familiar muy prolongado. Así nació en ellos una seguridad en todo su procedimiento, procedimiento que se parece al de las matemáticas; puede decirse, sin temor de exagerar, que calculan con sus ideas". "Cuando los jurisconsultos romanos tienen que considerar un caso de derecho, parten de la vida intuición de éste, $y$ ante nosotros se desarrolla poco a poco y plenamente, como si tal caso debiera ser el punto inicial de toda la ciencia que del mismo deba deducirse. Para los jurisconsultos romanos no hay una distinción clara entre la teoría y la práctica: la teoría se lleva hasta la más inmediata aplicación y la práctica se ve siempre elevada a la altura del proceso cientifico. En cada teorema fundamental, se ve a un mismo tiempo un caso de aplicación, así como en todo caso práctico se descubre la regla que lo informa".

Este es el método de la jurisprudencia. Por todo ello la legislación debe ser entendida como disposiciones provisionales o meras instrucciones dirigidas a los tribunales. La historia romana, señala Savigny, enseña que cuando el derecho se encuentra en progreso vivo no se siente necesidad alguna de codificación. Lia marcha hacia la codificación, dice Savigny, es siempre ocasionada por la incontrastable decadencia del derecho,

No hay que desdeñar, sin mảs, a la legislación. Es preciso reconocer el esfuerzo de compilar el derecho. Pero en este sentido la legislación debe ser atendida como indicaciones que reflejan las tendencias del derecho cosuetudinario para que la legislación realice una dirección semejante a la que en Roma ejercía el edicto del Pretor.

Los postulados del método histórico Badenes pueden ser reducidos a tres: empirismo, relativismo y intirnacionalismo.

4. Consecuencias y efectos. La escuela histórica incorpora el anảlisis histórico a la jurisprudencia. Con la Escuela Historica (con F. Von Sa- 
signy) la jurisprudencia adquiere un carácter sistemático. La escuela històrica inicia, en cierta medida. la lógica jurídica al referirse a los teoremas y a la argumentación del jurisconsulto (tomando como modelo la jurisprudecia romana, clásica). Con esta escuela se inicia la dogmática jurídica y la más sotlida construccion doctrinal.

5. Critica. Primeramente se señala que el método de esta escuela evita un planteamiento axiológico. ¿Cómo deferminar si to que se ha sido derecho vale intrinsecamente como derecho?

Otra crítica se dirige a la idea de que el derecho aparezca como un proceso pacifico, paulatino e imf erceptible. Se olvida que en muchos casos el derecho se desenvuelve y perfecciona a través de la lucha de clases, a través de una leqislación de objetivos conscientes inspirada por ideas jurídicas de oportunidad y progereso. La crítica más contundente se refiere a la idea de la realidad de una alma nacional Señalando que la idea del alma nacional es una tendencia mistica más que una observación de los hechos.

\section{La Jurisprudencia Dogmática}

1. Contexto e ideologia normativa. La escuela de la jurisprudencia dogmática tiene a su más ilustre y genial representante, especialmente a lo que a métodos de interpretación se refiere, a Rudolf Von Ihering (1818-1892). El auge de las ciencias cmpiricas empieza a manifestarse en las humanidades. La jurisprudencia necesita dejar de ser un conjunto de glosas y recetas praicticas para convertirse en ciencia, en el riguroso sentido de la palabra. La jurisprudencia se ocupa de un derecho positivo para construir, a partir de él. un sistema unitario y coherente. El medio para construir este sistema es la 'logica jur idica'.

2. Caracteristicas de la escuela. El presupuesto básico de la teoria dogmática es el positivismo. La mision de ta ciencia juridica es investigar los materiales concretos suministrados por el derecho positivo, elaborado y formar una unidad sistemática mediante procedimientos lógicos. $\mathrm{La}$ jurisprudencia dogmática tiene que construir un sistema coherente y unitario a partir de cualquier derecho positivo. El sistema jurídico - construido por la jurisprudencia - es un conjunto de normas, reglas y principios juridicos. que permite regular cualquier caso posible de la vida social. De ahí que no existan lagunas, Las incongruencias e incertidumbre de la ley son siempre satisfechas mediante la creación de normas derivadas de los principios generales del sistema. 
El sistema jurídico se construye primero inductivamente partiendo del derecho positivo, en cierta forma de la legislación. Se busca lo general hasta llegar a los principios o dogmas generales en los cuales todas las disposiciones unitarias orgánicamente convergen. Todas las consecuencias lógicas de tales principios o dogmas son también reglas que van a completar el sistema. Es importante señalar el carácter normạtivo que tiene el sistema. Los principios generales de otras ciencias tienen sólo un valor cognoscitivo.

Los dogmas establecidos por la ciencia juridica dogmática tienen fuerza y potestad vinculatoria. tivo).

3. La interpretación de la ley (determinación del derecho posi-

A partir de la jurisprudencia dogmática, el problema de interpretación de la ley se convierte en una parte del problema general de la determinación, formulación y aplicación del derecho en general.

Para Ihering la interpretación de la ley es parte de la construcción del sistema jurídico.

Ihering concibe a la ciencia política como aquél procedimiento que nos lleva a la construcción de un orden sistemático del derecho.

Según thering (El espiritu del Derecho Romano), para conocer el derecho y crear un orden sistemático, el jurista recurre a dos medios básicos que son: a) La simplificación cuantitativa, y b) La simplificación cualitativa. La primera se refiere a la selección del material juridico y se reduce al primado de hacer todo lo posible con el menor número de elementos. La simplificación cuantitativa se halla integrada por las siguientes operaciones: 1) Análisis de la materia, 2) Concentración lógica, 3) orden sistemático, 4) Terminologia jurídica apropiada, 5) Empleo correcto de aquello que existe. En la simplificación cualitativa toda la idea es la construcción juridica.

La interpretación es el primer paso que realiza el jurista para la construcción jurídica. La interpretación explica la materia juridica (resuclve contradicciones, disipa obscuridades, etc., clarifica la 'voluntad del legislador ${ }^{2}$, con objeto de determinar los principios en que esta materia jurídica se encuentra fundamentada y obtener el alcance de todas sus consecuencias. Esta interpretación de la legislación no agota la labor del cono- 


\section{LOS SISTLMAS DE INTERPRETACION}

cimiento del derecho ni condiciona totalmente la aplicación del mismo. Es necesario pasar a la jurisprudencia superior, que consiste justamente en la conclusión sistemática del orden jurídico. La característica de los sistemas jurídicos es su completitud. De ahí que todo caso concreto supone una regla abstracta aplicable aunque haya sido creada por medio de una inferencia $o$ argumentación jurídica.

La construcción juridica, de acuerdo con thering, esta sometida a ciertas reglas básicas: a) La construcción doctrinal (sólo podría haber construcción doctrinal) debe aplicarse exactamente al derecho positivo. De ahí que la legislación adquiera una singular importancia por la facilidad de acceso y conocimiento. Cabe señalar que, de acuerdo con thering. el legislador no construye; él presenta un derecho, el derecho dado. La construcción es obra de la ciencia juridica, la construcción parte del derecho dado (del cual el legislado es una gran parte). La construcción respeta el contenido de ese derecho dado pero tiene completa libertad de formas en la via de la construcción del orden sistemático del derecho; b) Ausencia de contradicción. Esto es inmanente a la teoría de la construcción, puesto que las construcciones doctrinales que realiza la ciencia juridica no pueden ser inconsistentes ni contradictorias; c) La belleza juridica.

Esta regla no tiene la misma importancia en cuanto condición de la construcción. Sin embargo, señala thering, la ciencia jurídica requiere un verdadero estilo artístico entendiendo por ello la sencillez, la claridad, la transparencia, etc.

El resultado de este procedimiento es el sistema juridico; sistema que sólo puede ser conocido por los juristas mediante su educación y métodos jurídicos de la argumentación. Dicho sistema va a proveer al juez o al jurista de una regla abstracta para solucionar todos los casos que la variedad de situaciones de la vida social les presente. Este es el procedimiento de interpretación del derecho positivo. Todas las incertidumbres, incongruencias y lagunas de la ley serán resueltas, deduciendo, de los principios (dogmas) del sistema, normas aplicables al caso concreto.

La lógica propia del sistema de la construcción juridica no sólo sirve para conocer y sistematizar el derecho, sino que es fuente de nuevas reglas juridicas $(o$, como cree el jurista dogmático, reglas existentes, pero hasta entonces desconocidas) encontradas mediante la interpretación.

4. Consecuencias y efectos. Puede decirse, quizis sin error, que las escuelas historica y dogmática del derecho, produjeron los más grandes 
adelantos de la ciencia juridica alemana. Vale señalar aqui que su influencia fue decisiva en la producción doctrinal de la escuela alemana de derecho privado. Influencia que se traduce en el código civil alemán.

Critica a la escuela dogmática a) Se señala que la jurisprudencia dogmática, en razón de su formalismo en base a positivismo jurídico, ignora la axiología jurídica. Una evaluación sobre el derecho positivo que no sea desde el punto de vista de elementos que lo trascienden no permite una crítica y una elaboración adecuada del derecho; b) Otra crítica señala que nada nos garantiza que la construcción llevada a cabo por la ciencia jurídica sea una construcción correcta y por tanto nada nos garantiza que las deducciones de reglas particulares de los principios bases del sistema sean correctas: c) Debida su atención, casi exclusivamente, a la sistematización del material jurídico dado, olvidado los procesos sociales.

\section{La jurisprudencia de conceptos (Escuela de Leipzig)}

1. Características, La escuela de Leipzig tiene como punto de partida el derecho positivo (cuya fuente principal, sobre todo para la claboración y análisis de conceptos, es el derecho legislado). El representante más ilustre de esta escuela es Bernard Windscheid, quien "trató los conceptos jurídicos con un método normativo riguroso, con exactitud matemática y filológica, teniendo como fin la libertad de discusión sistemática para la realización de la máxima garantía jurídica".

2. Interpretación de la ley. Es importante senalar que en la jurisprudencia de conceptos (Begriff jurisprudentz), al igual que en la jurisprudencia dogmática, el problema de la interpretación de la ley (del derecho legislado) es parte de su metodología. La interpretación de la ley se encuentra subsumida dentro del problema, más general, de la interpretación del derecho (si bien hay que recordar que para la jurisprudencia dogmática como para la jurisprudencia de conceptos el derecho legislado constituye la mayor parte del derecho positivo).

Considera Windscheid que la interpretación es aquel procedimiento analítico que permite superar la incertidumbre y adscribir a los términos de la legislación un significado apropiado. Pero la interpretación determina los conceptos contenidos en las normas; para, luego, reducirlos en sus partes constitutivas. 
Pensemos, verbigracia, en el problema de la compraventa.

Primeramente, encontraremos que las reglas relativas a la compraventa se encuentran contenidas en muy diferentes disposiciones, las cuales pueden estar en muy diferentes legislaciones. El primer paso es determinar y aislar los conceptos especificos que concurren en la compraventa. El segundo paso consiste en desarrollar los conceptos contenidos en las disposiciones relativas, resolviéndolos y reduciéndolos a sus partes constitutivas indicando los elementos contenidos en ellos.

En la compraventa, por ejemplo, se tendrían que analizar los conceptos de los cuales ésta se integra.

Si la compraventa es un contrato, es necesario saber qué es un contrato. Si el contrato es un negocio jurídico, habrá que determinar qué es es el negocio jurídico. Si éste es una declaración de voluntad privada, es necesario determinar qué es declaración de voluntad.

Si en la compraventa se transmite una cosa por dinero, habrá que determinar qué es 'cosa', quê es 'traditio', qué es relación, acuerdo, etc.

Habiéndose analizado perfectamente todos los conceptos y desarrollados los elementos contenidos en aquéllos, entonces, de acuerdo con Windscheid, tendremos una inteligencia completa del contenido de los conceptos del derecho y una plena inteligencia del derecho positivo. Esto garantizará la seguridad de su aplicación.

3. Consecuencias e importancia. La importancia de Windscheid en la ciencia del derecho y, en general, de la escuela de Leipzig es inestimable.

Windscheid, no obstante ser el más grande de los pandectistas, tuvo discipulos de enorme talla aun fuera del derecho romano: de Binding (en el campo de la teoría penal), de Wach y de Helwig (en el campo del derecho procesall, de Stcin.

Grandes fueron los productos de las escuelas histórica, dogmática y de conceptos alemanes reseñados. Pero habia que señalar dos: la Escuela del Derecho Privado Alemán y la Allgemeine Staatlehre.

El derecho privado alemán se caracteriza por incorporar los estudios de derecho romano desde un punto de vista científico y sistemático. Se aprovechan sus métodos y para el estudio del derecho germano. Claro 
ejemplo de todo esto es el codigo alemain de 1900. De entre vanos miembros de la escuela del derecho privado alemán se puede citar a Enneccerus. Kipp, Wolf, Von Thur. Una mención especial dentro de la sistemática del derecho privado merece el profesor Otto Von Gierke.

La escuela de Allgenteme Staarslehre es tambièn resultado de las escuelas alemanas del derecho. especialmente de la jurisprudencia de conceptos. Sus más imporantes representantes son Laband Gerber, Jellinek (creador de una teoría juridica del Estado), los cuales son pilares del derecho putblico en el mundo. Es pues a partir de Savigny. Thering. Windscheid (para citar a los jefes de las escuelas) que la idea de ciencia que informa el estudio del derecho cobra una muy alta expresión.

La Escuela de Leiprig es el paso inmediato anterior a la aparición de las obras especificas de filosofia juridica que inicia Rudolf Stammler y que irian a cobrar enorme importancia con la escuela de Viena. A partir de entonces, la intepretación ya no es aspecto metodológico de la ciencia del derecho, sino un elemento del procedimiento de creación del derecho. $\mathrm{La}$ interpretación juridica para la jurisprudencia dogmática es una actividad tendiente a reformular el derecho positivo.

\section{La Jurisprudencia de Intereses (Escucla de Tubingen)}

1. Contexto e ideologia normativa. Es thering tambien el punto de partida de esta escuela. La jurisprudencia de intereses es probablemente la dirección metódica que ha log̣tado una mayor popularidad.

El principal representante de esta escuela es Philip Heck. La juris. prudencia de intereses es una reacción contra la jurisprudencia de conceptos, y. además, un nuevo método. Fstudia el derecho teniendo en cuenta la vida, sustrayéndola del primado de la lógica donde estuvieron sumergidos largo tiempo. Los elementos que maneja la jurisprudencia de intereses pueden ser muy variados (económicos, científicos, ideales religiosos. etc.). todos ellos alimentan la vida humana.

Esta es la vida humana que se impone a las normas. E1 papel de la jurisprudencia de intereses es obtener conceptos ordenadores que nos permitan sistematizar los mandatos y los intereses. con objeto de llevar a cabo una elaboración y clasificacion, buscando constantemente y en el ültino término un efecto sobre la vida concreta.

2. Cancterisficas. Las principales características de la jurispruden- 


\section{LOS SISTIMAS DE INTERPRETACION}

cia de intereses son las siguientes: a) Funda en la experiencia toda decisión que no sea deducida directamente de la ley; b) Otra característica que le ha dado el nombre a la escuela es la importancia que concede al concepto de interés, la vida es un complejo de intereses que se mueven en distintas direcciones produciendo incesantes conflictos. Estos conflictos de intereses reclaman normas capaces de superarlos. c) En contrapartida con las otras escuelas jurídicas en que la determinación del derecho aplicable no es sino uno de los momentos de la determinación del fenómeno jurídico, la determinación de la norma aplicable es todo el método de la jurisprudencia de intereses.

Podria decirse que la jurisprudencia de intereses es únicamente el método o un conjunto de procedimientos que nos permitan encontrar el derecho aplicable dejando a un lado la misión ordenadora de la ciencia y la formación de conceptos.

3. Interpretación de la ley. Pará interpretar el derecho positivo, para encontrar la decisión e interpretar la ley superando sus incertidumbres y lagunas, el juez debe de ponderar los intereses que han tenido lugar en la creación de la ley. El juez debe reproducir los elementos de interés que existieron durante la creación de la ley para saber especificamente cuál es el equilibrio que la ley trata de imponer. Si el derecho es el resultado de fuerzas, es necesario que el juez pondere precisamente las fuerzas que Je dieron origen. Una vez ponderadas y comprendidas, el juez está en posibilidad de captar la finalidad de la ley para poderla aplicar en casos similares o a casos extensivos. La escuela de Tubingen centró la esfera de la investigación a la mera práctica del derecho.

4. Consecuencias y efectos. La jurisprudencia de intereses introduce en el estudio del derecho en el terreno de la práctica, en la búsqueda del derecho aplicable la idea de finalidad, por una parte; $y$, por otra, incluye la idea de intereses ( $\mathrm{si}$ bien ésta ya aparece en la dirección de Ihering).

La inclusión del teleológico permite en la práctica encontrar gran cantidad de soluciones paralelas siempre que se determine la finalidad u objetivos perseguidos por la legislación. De esta manera, el juez puede encontrar padrones que permitan hacer extensivas las leyes a casos similares, mientras satisfagan el mismo género de intereses y el mismo género de finalidad. Por otro lado, la idea de incluir interés imprimió un nuevo giro a la investigación juridica, haciendo más empirica y concreta la observación del derecho. 
5. Crítica a) El método de la jurisprudencia de intereses carece de aplicación ordinaria. Dice Stoll que, en gran nùmero de tases, el juez se conforme con la subsunción logica sin realizar c incluso sin poder realizar (por falta de tiempo conocimientos. información, etc.) una ponderación de los intereses que participan en la claboración de las leyes o que son paralelos a la elaboración de las leyes. De esta mancra, el juce decide subsamiendo el caso dentro de la norma general, o bien declarando non liquet. b) Dedica poca importancia a la teoría del derecho: el $\mathrm{El}$ interís no puede erigirse en el único criterio metódico; el derecho no es simplemente el resultado o la superestructura de los intereses o el reflejo de los intereses. Las normas juridicas ordenan intereses. La sentencia judicial decide sobre los intereses, compone conflictos de intereses. Pero no simplemente se adhiere al interés preponderante; d) Existe gran cantidad de actividades humanas que no son juridicamente consideradas en base a conflictos de interés (tales como matrimonio, las relaciones de filiación, de patria potestad, etc.).

\section{La Escuela Científica Francesa}

1. Contexto e ideologia normativa, La Escucla Cicntifica Francesa representa una crítica definitiva a los métodos tradicionales siendo, a su vez, una nueva concepción metođológica. Rechaza el fetichismo legalista asf como el riguroso conceptualismo. Sin duda, Francois Gieny es el autor más distinguido de esta escuela. Podria decirse que Geny es para la ciencia juridica francesa, lo que para Alemania lo son thering o Windscheid. Geny emprende una critica al método tradicional de interpretaciôn del derecho: primeramente ataca la identificacion de la ley escrita con el derecho, posición positiva de varias escuelas, particularmente de la escuela de la exégesis.

La escuela es principalmente una reacción en contra de los procedimientos mecánicos de interpretación y aplicación del derecho. A este res. pecto. Geny considera que el jurista debe ser un hombre que medite sobre los datos de la naturaleza para organizar metódicamente el derecho y dirigir racionalmente la acción.

2. Características, El punto de partida de la obra de Geny es la distinción entre ciencia y técnica, la cual tiene como base la distinción entre el dato (donné) y lo construido (contruit). El dato formula la regla de derecho tal como resulta de la naturaleza de las cosas. Lo contruido hace referencia al trabajo artificial que tiende a establecer la regla juridica en precepto susceptible de influir en la vida. Esto es. Ia ciencia tiene por 
objeto constatar los datos de la naturaleza y los hechos; el contenido de la técnira es la constiturión jurílica, l,os datos pueden ser naturales, históriem, racionales o idealrs. La técnica, por su parte supone dos procedimientos: la creación de formas y la determinación de conceptos. Entre las formas se encuentran las fuentes formales del derecho positivo (la ley, la costumbre, la jurisprudencia, la doctrina). Los conceptos son las operaciones fundamentales que lleva a cabo el jurista para la construcción del sistema positivo.

3. La interpretación de la ley. Geny parte de la tesis de que la ley no es la única fuente del derecho; ciertamente la ley es la fuente más importante del derecho moderno. La ley, según Geny, no puede ser un mero producto racional, en su elaboración intervienen elementos irracionales, fácticos, psicológicos, biológicos, económicos, etc. Geny considera un error oponer la interpretación gramatical a la interpretación lógica: ambas se complementan. Tampoco se puede plantear una opción entre el texto y el espiritu de la ley.

Si una distinción puede ser hecha, es la interpretación mediante la fórmula del texto y la que se obtiene a la ayuda de elementos extraños a esta fórmula. Antes que todo - señala Geny-es a la fórmula del texto a la que hay que preguntar por la 'voluntad del legislador'.

En el momento que esta 'voluntad' se desprende del texto sin ser contradicha por ningún elemento exterior, ella dictará suprimiendo toda interpretación la decisión del intérprete. Siendo la ley el producto de la actividad consciente y reflexiva de su autor, no solamente él ha debido representar exactamente la regla que él entendía establecer, sino que debemos suponer igualmente que ha escogido, con reflexión y premeditación. las palabras que traducen fielmente su pensamiento y su voluntad. Es pues a la formula de la ley a la que se debe uno dirigir inmediatamente.

Sobre las concepciones jurídicas o definiciones que utiliza el legislador Geny, se pronuncia por no desconocer estas concepciones formuladas en el texto, pero que deben de ser entendidas vinculándolas lo mís posible a las reglas positivas y desarrolladas en última instancia con gran moderación.

La búsqueda de la 'voluntad' legislativa, segùn el contenido mismo del texto implica - dice Geny - una lógica intima, inherente al lenguaje inteligente sin el cual las palabras se mantendrian vacias de sentido... esta Kgeica. que trabaja sobre las palabras, se convierte más fecunda que el texto de la ley misma, en la medida que hace ver el texto de la ley no co- 
mo una proposición aistada, sino somo ta fracciór de din conjunto tomado en sa unidad y en sis totatidad. Debemos fecurrir a sarias disposiciones, como qujera que éstas se cocouentren en los textov lequles o en difercntes textos legales. para construir una troposictón razonahte a partir de thistintas disposiciones.

Como la ley no es solamente fenomeno psicologico sino quie es al mismo tiempo un fenómeno social, bañado de una atmósfera especial que le determina, es necesario que se tenga en cuenta ciertos elementos exteriores al texto a interpretar, sin los cualcs dicho texto se mantendr ia mudo o no revelaria sino de manera incompleta la voluntad que contienen.

Estos elementos exteriores pueden senalarse entre otros, los elementos que el legislador ha querido organizar a los cuales la disposición del legislador debe satisfacer. De esta manera se descubre la finalidad propia de la ley la ratio legis. Esto permite buscar medios idóneos para el mejor cumplimiento de la nario legis. Otro grupo de elementos externos se encuentra en la observación del medio social del cual la ley ha salido. La ley que se encuentra determinada por acontecimientos (Occotio Legis), por el análisis de las concepciones juridicas reinantes y la influencia de legislaciones extranjeras y de ambientes juridicos o de escuelas juridicas. Todos estos elementos y todos aquéllos que podrian incluirse todavia, me parecen, dice Geny, legítimamente empleados para arrancarle al texto legal su enigma y para penetrar mejor su sentido pero a condición de que se dirijan a descubrir la 'voluntad del legislador'. Esto es, mientras no contradigan directamente el texto de la ley.

Cuando se hace intervenir a ta historia para actarar el teato de la ley no es, no debe ser, la verdad histórica to que se ha de buscar, sino solamente el ambiente histórico del legislator.

Los principios generales del derecho brindan una gran ayuda en la interpretación de la ley siempre que no se busquen los principios jurídicos en si, sino especificamente las concepciones mas adaptadas a la finalidad propuesta que es la interpretación de la ley.

El limite de la interpretación de la ley está cuando se encuentra no sólo ante obscuridades e incertidumbres sino ante lagunas. En este caso no es posible encontrar la "voluntad del legislador", no podemos rastrearla por ningún bado. En este momento aparecen otros procedimientos que no son la interpretación. Es, pues, necesario clistinguir, de acuerdo con Geny, dos procedimientos en la búsqueda de reglas juridicas: a) La interpretación 
que consiste en superar las incertidumbres y obscuridades de la ley; b) La libre investigación que consiste en la elaboración de las reglas jurídicas con independencia de la ley escrita.

Geny señala que el intérprete no puede olvidar la existencia de las demás fuentes formales. Estas pueden ayudar a la interpretación de la ley.

4. Crítica. Nos vamos a constreñir sólo a los procedimientos de interpretación de la ley y no de todo el sistema de Geny. La primera se dirige a la separación entre la ciencia y técnica. Doanti y Bonnecase seflalan que dicha separación es imposible. La técnica jurídica no es un momento cronológico o sistemáticamente sucesivo al de la ciencia sino que constituye con ésta una unidad conceptual. Otra crítica señala que en el dominio de la interpretación de la ley el método de Geny no se diferencia del método dominante; que reposa sobre el mismo postulado fundamental de la inmovilidad de las reglas juridicas. Sólo en el dominio asignado a la libre investigación científica (especificamente en el de la integración) es donde el método de Geny se separa de los métodos dominantes.

\section{El cambio de Giro}

Podría encontrarse que en los métodos de interpretación que hemos observado existen dos características comunes a todos. a) Los métodos tienen como finalidad encontrar un 'derecho aplicable' legislado o no; b) Otra característica de los métodos de interpretación es que al buscar el 'derecho aplicable' pretenden, consciente o inconscientemente, dar una formulación sistemática al derecho. La argumentación procura que se produzca un sistema coherente en su aplicación. Si el derecho (ya sea precedentes, legislaciones, etc.) tiene incertidumbres, lagunas o vaguedades, los métodos de interpretación intentan, consciente o inconscientemente (quizás sea una mera ilusión del jurista), la construcción de un sistema. El sistema se genera así, a través de los métodos de la aplicación.

\section{El Sociologismo y la Escuela del Derecho Libre}

1. Contexto e ideologia normativa. Nació con el objeto de atacar la idea mística del jurista y substituir la técnica jurídica para la correcta aplicación del derecho, La escuela del derecho libre es la primera escuela que da una explicación de la interpretación. Esto es, de lo que efectivamente hace un juez cuando busca la norma aplicable. Varios autores 
representan esta tendencia - la cual tuvo muy diferentes modalidades-. Sin embargo, de entre todos ellos puede señalarse a Hermann Kantorowicz y a Eugen Ekrlich.

2. Características de la escuela. Frente al derecho estatal Kantorowicz presenta un derecho libre, el cual no es derecho natural sino, simplemente, el derecho de los individuos y de la comunidad. El derecho libre es un derecho positivo, detrás de el se encuentra un poder, una voluntad, un reconocimiento. Seflala Kantorowicz que el viajero en un país extranjero se hace familiar con la lengua, historia, arte y costumbre del pueblo, pero ni por sueños se le ocurre ni siquiera abrir sus códigos. Todos ellos viven con arreglo al derecho libre, de acuerdo con aquello que las opiniones de su círculo o su juicio individual les presenta como derecho, no como arbitrariedad o mera conveniencia. El derecho libre, dice Kantorowicz, constituye el suelo del que el derecho estatal dimana casi todos los pensamientos legislativos que han existido, con anterioridad, como principios del derecho libre. A este respecto, sefiala Ehrlich que frente al derecho del Estado frente a las leyes existe un derecho dinámico y concreto, un derecho vivo de la vida social.

3. La interpretación de la ley. La escuela del derecho libre señala los procedimientos de interpfetación (o integración) son, en gran medida, ficticios. Se basan en la "suposición ingenua e inconsciente de que exista un legislador que tenga exactamente los mismos deseos del que emplea los métodos de interpretación". La razón no desempeña el papel decisivivo en los métodos de interpretación o en la búsqueda de los argumentos para las decisiones judiciales. Este papel corresponde a la voluntad. Los métodos de interpretación (o integración) se inspiran en la voluntad de conseguir el resultado deseado. Una interpretación no parece reunir todas las cualidades ni sus consecuencias pueden ser deseadas por nosotros. Esto ocurre con la interpretación extensiva, la analogia, la ficción jurídica, así como la natio legis. El procedimiento de la interpretación revela que el intérprete escoge entre las premisas posibles aquéllas que suministran conclusiones deseadas. Este procedimiento, en consecuencia no resulta de la razón sino de la voluntad.

Los juristas nos han hecho creer que, mediante la interpretación, las reglas aplicables al litigio son deducidas de conceptos generales del derecho, conceptos que, a su vez, son obtenidos inductivamente de la ley. En realidad, lo que hace es resolver los litigios mediante un acto de voluntad, los procedimientos metódicos para argumentar no son sino el disfraz con el cual le dan prestigio a su fallo. Dice Kantorowicz que Bartolo, el 
más famoso de todos los juristas (sic), primeramente dictaba la resolución y luego hacia buscar a su amigo Tigrinio los pasajes aplicables en el Corpus luris. Kantorowicz identifica los procedimientos (de interpretación y construcción) de la jurisprudencia dogmática -en sentido lato- con los de la teologia ortodoxa.

El jurista basa (o hace creer que basa) todas sus resoluciones en la ley, la iglesia reconduce cada una de sus instituciones a pasajes de la sagrada escritura. En la interpretación, la teologia ortodoxa y la jurisprudencia dogmática, lo que existe es un acto de voluntad del actor. La deducción lógica no pása de ser mera aparienicia: no está al servicio de la verdad síno del interés.

4. Consecuencias, De lo expuesto podemos encontrar que la interpretación es un acto de decisión, los elementos de razón son mera apariencia. Tal situación, dice Ehrlich, es habitualmente obscurecida porque los jueces y los juristas, cuando resuelven una controversia pretenden justificarla invocando los artículos de una ley, principios jurídicos o reglas de argumentación jurídica. Ehrlich estima indispensable destruir esa falsa 'Iógica' jurídica para dejar libre el terreno a la observación metódica y a la aplicación práctica del derecho vivo.

Desenmascarando tal procedimiento, la ciencia no se contentará con el papel de humilde sirvienta del legislador. Las necesidades de la vida jurídica exigen que la ciencia del derecho tenga una función creadora. La ciencia del derecho proporcionará definiciones, conceptos; pero no por construcción sino dotándoles de aquellas características que los principios del derecho libre suministran. Si la voluntad ha sido elemento integrador de las lagunas, entonces corresponde al derecho libre colmar las lagunas (de hecho siempre las colmó). La ciencia del derecho es una 'fuente del derecho'; al igual que el legislador, tiene que colmar las lagunas mediante la dirección del derecho libre. La misión de la ciencia deviene mayor, y menos modesta la ciencia del derecho constituye el descubrimiento libre.

5. Críticas. Como crítica fundamental podría señalarse la confusión entre ciencia jurídica y su objeto. La ciencia jurídica tendría la misma función que las autoridades: normar. ¿Quién realizaría la función de describir? 


\section{Un punto de Vista Personal}

1. Los tipos de interpretación. Los materiales jurídicos formulados por escrito (tales como leyes, constituciones, testamentos, contratos, etcétera) son, como cualquier otro lenguaje, objeto de interpretación. Pero, cabe preguntar ¿para qué se interpreta? o. bien, ¿quién o quiénes interpre$\tan$ ? Hemos visto que cualquiera que dote de significado un lenguaje (o los términos de un lenguaje) realiza o lleva a cabo una interpretación, de ahí que cualquiera que dote de sentido a estos "materiales juridicos", es decir, quienquiera que otorgue cierto significado al lenguaje jurídico escrito se encuentra interpretándolo. No obstante, es posible determinar dos grandes tipos de interpretación juridica, atendiendo a la situación que guarda el intérprete en relación con los materiales jurídicos que se van a interpretar. Estos tipos de interpretación pueden denominarse: interpretación orgánica $\mathrm{e}$ interpretación no orgánica.

a) La interpretación orgänica. Es fácil observar que los materiales jurídicos (constitución, leyes, etcétera) en razón de su función prescriptiva, se encuentrán dirigidos a ciertos individuos, los cuales tienen que hacer uso de estos materiales, es decir, tienen que aplicarlos. A los individuos que se encuentran en la situación de aplicar o ejecutar los materiales jurídicos los llamaremos órganos. Esto es, los órganos serán los individuos que tienen como función aplicar o ejecutar el derecho.

Claro que -tal y como podrá observarse en el curso de la explicación - todo acto de aplicación es también un acto de creación (todos los materiales jurídicos condicionantes son, por su propia naturaleza, más o menos incompletos). Cuando en este caso hablamos de órganos to hacemos de modo general sin importar si son órganos centralizados (funcionarios profesionales) o descentralizados (súbditos más o menos indiferenciados).

Ahora bien, para que un órgano aplique el derecho (constitución, tratados, reglamentos, etcétera) es necesario que establezca el sentido de los materiales jurídicos que tiene que aplicar. Cabe decir, para que el órgano pueda aplicar o ejecutar lo dicho por estos materiales es menester que los interprete.

La interpretación orgánica aparece cumo el acto de significación mediante el cual el órgano determina el sentido de los materiales jurídicos que él tiene que aplicar a fin de proseguir el proceso escalonado de creación del derecho, el cual se indica en la constitución y se termina en el 
thimo acto individualizado de ejecuctón.

De lo anterior se desprende que los materiales juridicos (constitución. ley, efcétera) que han de aplicarse, o mås exactamente, el lenguaje en que son expresados (lenguaje del constituyente, lenguaje del legislador, etcitera) recibe, por parte del órgano aplicador, una cierta interpretación de la cual depende la forma en que es aplicado el derecho.

La interpretación orgánica jucga, asi, un papel definitivo en el procedimiento de creación del orden juridico. En efecto, el órgano aplicador, al decidir el sentido que guarda el lenguaje juridico elaborado, decide, a su vez, el curso de la creación y aplicación subsecuente del derecho. En la interpretación orgánica la interpretación se traduce en actos o voliciones cuyo resultado son los materiales juridicos que completan un cierto sistema de normas juridicas (la significación es base del acto de decisión).

En el caso de la interpretación que hemos denominado orgánica, la significación dada a los materiales juridicos (o simplemente al derecho escrito) se manifiesta en un acto de voluntad más o menos arbitrario que decide el curso subsecuente de la aplicación y creación del orden jurídico positivo.

b) La interprefación no orgánica. La interpretación juridica no es monopolio exclusivo de los órganos aplicadores del derecho. Hemos visto que cualquicra que dote de significado el lenguaje juridico realiza una interpretación juridica. La interpretación no orgánica puede caracterizarse, por consecuencia, como aquélla que no es realizada por los órganos aplicadores del derecho (v.gr.: los profesores, los juristas, los particulares).

Si en la interpretación orgánica del lenguaje en que se expresa el derecho (constitución, ley, etcéteria) es interpretado por los órganos encargados de su aplicación, a fin de crear los materiales jurídicos que los completan (decisiones administrativas, sentencias, etcétera). en el caso de la internectación no orgániça el 'intérprete' es un elemento ajeno a la relación de aplicación.

FI acto de intetpretación que realisa el órgano aplicador es sicmpre -en atención a su carácter subjetivo más o menos orbitrario, El órgano uplicador, de entre todas las significaciones que es posible hacer, escogerá ana fla convenicnte, la conforme a la voluntad del legislador, ba justa, la viable, ctecteta). siguiendo para ello cicrtos métodos (el exegético, el de La escuela libre, etcétera), o haciendo caso ontiso de ellos. Asi pues, el 
sentido que se le da al lenguaje juridico dependerit de la cultura, de los sentimientos, instintos, credo político o religion, del órgano que lo interpreta.

No obstante to dicho, no debemos olv idar que los materiales juridi$\cos$ (constitución, leyes, tratados, etcétera) determinan siempre, en mayor o menor grado, las caracteristicas que deben tener los actos que los aplican para ser regulares. Sin enbargo, esta determinación no puede ser exhaustiva. En efecto, si existen constituciones es para que pueda haber leyes, decretos, etcétera; si existen leyes es para que pueda haber sentencias judiciales y decisiones administrativas. Esto es, los actos que reclanan una aplicación son, necesariamente, más o menos incompletos. Por tanto, sicmpre habrá elementos que serán adicionados por los sucesivos actos de aplicación.

Por exhaustiva que pudierà ser esta determinación ( $\mathrm{y}$ aun suponiendo que ésta fuera completa) no podría, sin embargo, evitar la interpretación que el órgano aplicador hace de estas determinaciones. Interpretación que, como hemos visto, es una apreciación significativa más o menos arbitraria de los materiales juridicos que se aplican. Efectivamente, al quedar en posibilidad de interpretar (acto que, como hemos observado, acompaña necesariamente a toda aplicación), el órgano aplicador incorpora o adiciona nuevos elementos a los materiales jurídicos existentes.

Ahora bien, puesto que el intérprete no tiene la posibilidad de aplicar el derecho que interpreta, entonces la interpretación no orgánica se agota con la sola significación dada al lenguaje juridico que se considera.

En el caso de la interpretación orgánica, la significación dada a los materiales que se aplican (constitución, leyes, etcétera) se manifiesta en actos de voliciones humanas que establecen otros materiales juridicos (reglamentos, sentencias, decisiones administrativas), los cuales van constituyendo progresivamente el orden jurídico. Estos materiales jurídicos son parte de la experiencia juridica; esto es, son derecho al igual que los materiales juridicos que aplican.

Por el contrario, en el caso de la interpretación no orgánica, la significación suministrada a los materiales juridicos no se manifiesta en actos de aplicación del derecho. En este caso, la interpretación no acompaña la producción de nuevos materiales jurídicos.

Ahora bien, si la interpretación no-orgánica no se traduce en mate- 
riales jurídicos, entonces la significación producto de esta interpretación no es parte de la experiencia juridica; es decir, no es derecho (éste se agota con los materiales que constituyen la experiencia jurídica). La interpretación no-orgánica es sólo signifucación (cognición, descripción, valoración, etcétera) del derecho.

2. Los lenguajes juridicos. Hemos dicho que los materiales jurídicos constituyen un lenguaje o, en todo caso, son formulados en un lenguaje.

A este lenguaje, en razón del carácter prescriptivo de los materiales juridicos, los denominaremos Lenguaje juridico prescriptivo. Como es de suponerse, los materiales jurídicos que resultan de la interpretación o aplicación de otros son también parte del lenguaje prescriptivo. De manera que, en la interpretación orgánica, la significación que se da al lenguaje jurídico prescriptivo (por ejemplo: el lenguaje del constituyente) es expresida en su lenguaje prescriptivo (v.gr.; en el lenguaje del legislador). En el caso de la interpretación no orgánica, el lenguaje prescriptivo en que estos materiales se encuentran expresados (lenguaje del constituyente, del legislador o del juez), no es un lenguaje prescriptivo sino de carácter declarativo o enunciativo.

Es importante distinguir estos dos niveles de lenguaje para cvitar grandes confusiones y paradojas. En particular, debe distinguirse perfectamente cuándo se trata de una interpretación orgánica (la cual forma parte del lenguaje prescriptivo) puesto que -como dice Kelsen-los actos juridicos que se formulan en palabras o por escrito contienen ellos mismos alguna indicación sobre su significación. Esto, dice Kelsen, es una particularidad de los materiales juridicos. Esta autointerpretación, sin embargo, no es sino parte del lenguaje prescriptivo, objeto también de la ciencia del derecho,

En otro lado, Kelsen dice al respecto que "esta es una de las particularidades de los hechos estudiados... por la ciencia del derecho. Una planta no puede comunicar nada sobre sí misma al botánico que la examina: no trata de dar de sí misma una interpretación científica. La Ciencia del derecho se encuentra asi, muy a menudo, en presencia de una interpretación que es suministrada por los mismos hechos (materiales juridicos) y que se anticipa a la que deberá establecer un examen cientifico" (el del lenguaje juridico cognoscitivo).

Pues bien, mientras los materiales juridicos (comportamientos o voliciones humanas) crean o establecen el derecho, las proposiciones que componen el lenguaje de la ciencia del derecho conocen el derecho, no lo 
elaboran.

Una ciencia, en tanto tal, se agota en el conocimicnto de sus objetos. De modo que una ciencia del derecho, en tanto que ciencia, no puede más que conocer su objeto: el derecho; $y$, en base a ese conocimiento. describirlo y analizarlo, Sin embargo, la "ciencia" juridica tradicional bajo la apariencia de un conocimiento del derecho no hace sino tratar de reformularlo. Esto es, procura influir al órgano creador con objeto de modificar el orden jurídico positivo en el sentido en el que el jurista desea (es, pues, un acto de valoración y de voluntad). A esta "ciencia" la denominaremos jurisprudencia dogmática en contraposición con la ciencia del derecho que se agota en el conocimiento de su objeto.

En tanto que la significación de la ciencia juridica es únicamente un acto de conocimiento, el establecimiento del dereeho (la aplicación de materiales jurídicos y el establecimiento de otros) es un acto de voluntad que crea el orden jur idico. La significación que suministra la ciencia del derecho a los materiales jurídicos que interpreta, no se manifiesta en actos de aplicación del derecho (la ciencia del derecho no legisla, no condena, no ejecuta), se concreta sólo a conocer el derecho, $y$, en base a ese conocimiento, a describirlo y analizarlo. Asi pues, el lenguaje que constituye la ciencia del derecho enuncia pero no prescribe.

Muy frecuentemente - sostiene Kelsen-se ignora la diferencia que existe entre la función de la ciencia del derecho y la función de la autoridad jurfdica (los organos del derecho), y, por consecuencia, entre el producto de la primera y el producto de la segunda. Asi, por ejemplo, en el lenguaje ordinario las palabras "derecho" y "ciencia del derecho" aparecen como expresiones sinónimas.

En verdad -continúa Kelsen - la ciencỉa del derecho no puede más que describir el derecho, la ciencia del derecho no puede prescribir tal y como lo hace la autoridad jurílica. Ningún jurista puede negar que existe una diferencia esencial entre una ley publicada en el diario oficial de un Estado y un comentario hecho sobre esta ley, obra de la doctrina, o entre el codigo penal y un tratado de derecho penal, $O$ bien -agregaríamos nosotros - entre una constitución y una explicación de esa constitución (obviamente nos referimos a la ciencia jurídica y no a la jurispradencia dogmática).

Así es como Kelsen distingue entre función juridico-prescriptiva. consistente en prescribir o normar el comportamiento humano, asignán. 
dole un especifico significado (por ejemplo: legislador, contratante, homicida, etcéterá) y la función cientifica juridica que consiste cn conocer cl derecho.

Al lenguaje mediante el cual la ciencia del derecho otorga cierto sentido a los materiales juridicos que conoce, podemos denominarlo lenguaje juridico cognoscitivo, en oposición al lenguaje jurídico prescriptivo en que se manifiesta el derecho, propio de los órganos creadores del orden juridico ( $y$ en oposición al lenguaje valorativo-prescriptivo de la jurisprudencia dogmática). De acuerdo con esto, resulta que podemos diferenciar cuando menos, dos sistemas de significación o interpretación jurídica; o mejor, dos lenguajes jurídicos: el derecho (sistema de materiales juridicos que proporcionan una significación jurídico prescriptiva) y la ciencia del derecho, sistema de enunciado que proporciona la significación jur ídicocognoscitiva.

De acuerdo con un ampliamente aceptado punto de vista, tencmos que considerar a la ciencia como un conjunto de proposiciones o enunciados cuya estructura y sentido dependen de reglas o principios básicos que las hacen posibles y, por tanto, reconocibles como entidades del conjunto que constituye el conocimiento científico. En otros términos, puede decirse que la ciencia no es más que un lenguaje organizado a partir de ciertas reglas explicativas. "La ciencia - afirmaba Condillac-es un Ienguaje bien hecho".

"Siempre que hablamos de una teoria o sistema filosófico nos estamos refiriendo slirecta o indirectamente, o al menos asf lo parece, a un lenguaje formalizado, esté o no formulado explicitamente tal lenguaje:"

Estos lenguajes jurídicos, en tanto tales, esto es, en lo que a su función significativa se refiere, se distinguen entre sí de una manera precisa: en primer lugar, porque son lenguajes de niveles diferentes.

Con respecto a esta función significativa, dice J.C. Smith que "a partir de las investigaciones de Husserl, el problema lógico de la norma jurídica la sido planteado no ya de un modo estrictamente formal, sino atculićndose a la función que la misma cumple como significación, función que viene siendo identificada, en lo esencial, con la del juicio enunciativo". "Admiten, en efecto, que las diferencias funcionales que existen entre un juicio y una norma son sólo diferencias especificas, que en nada afectan a su común carácter esencial. Pues aun cuando la función del juicio consiste en enunciar y lis de la norma juridica consiste en imputar a 
un hecho antecedente un hecho consecuente, ambas funciones se identifican esencialmente en una genética, común en ambos casos: la función significativa". Tanto el juicio enunciativo como el "juicio normativo" adquieren su carácter significativo en virtud de actos de "dar significación" que pertenecen a un mismo género: "el de las intenciones significativas".

Las proposiciones que formula la ciencia juridica tienen como objeto las normas jurfdicas, es decir, las normas jurídicas constituyen el objeto o contenido de las proposiciones jurídicas. De manera que el lenguaje normativo constituido por las normas jur idicas es objeto del lenguaje normativo compuesto por las proposiciones de la ciencia del derecho. Así pues, las normas jurídicas serian, en relación con las proposiciones jurídicas, un lenguaje-objeto y estas últimas constituirian, en relación con las normas jur idicas, un metalenguaje.

El lenguaje que se usa para hablar acerca de un lenguaje que llama "metalenguaje". En cualquier investigación sobre lenguaje existe un lenguaje-objeto que constituye el objeto de investigación y existe un metalenguaje usado por los investigadores para. hablar del lenguaje objeto... Debe enfatizarse que el lenguaje-objeto y el metalenguaje son términos relativos. Cualquier lenguaje, no importa lo simple o complejo que éste sea, es un lenguaje-objeto cuando se habla de él. Y cualquier lenguaje es un metalenguaje cuando es usado para hablar (to discuss) de un lenguaje objeto". 